\title{
Lymphocyte blastogenesis to plaque antigens in human periodontal disease
}

\section{The relationship to clinical parameters}

\author{
Fredertc N. SMTth aNd NirLaus P. Lang \\ Dental Research Institute and Department of Periodontics \\ The University of Michigan and V. A. Hospital, Ann Arbor, Michigan, USA
}

\begin{abstract}
This study undertook to correlate lymphocyte transformation to human dental plaque antigens with clinical estimates of periodontal disease.

Forty-eight patients with periodontal conditions ranging from normal gingivae to severe periodontitis were examined clinically. Oral cleanliness was determined by the Plaque Index System (Silness \& $\mathbb{L}$ öe 1964) and gingival health was assessed using the criteria of the Gingival Index System (Löe \& Silness 1963). Pocket depth and loss of periodontal attachment from the cementoenamel junction (Ramfjord 1959, Glavind \& Löe 1967) were also measured. Triplicate microcultures of peripheral blood lymphocytes were stimulated with four different concentrations of human plaque antigens. The uptake of $\mathrm{H}$-thymidine during blastogenesis was measured by liquid scintillation counting.

There was no correlation between the stimulation by most of the isolated plaque antigens or pooled plaque and the periodontal conditions as determined by plaque index, gingival index, pocket depth and loss of attachment. Howewer, there was a significant, although low, correlation between clinical parameters and the stimulation of peripheral blood lymphocytes by $B$. melaninogenicus and $A$. viscosus. Stimulation with $B$, melaninogenicus correlated more highty with pocket depth and loss of attachment, while stimulation with $A$. viscosus and $A$. naesizndii correlated more highly with plaque and gingivitis scores. The possible role of these organisms in the pathogenesis of periodontal disease involving cellular immunity was discussed as was the interpretation of data obtained in blastogenesis using peripheral blood lymphocytes and its relevance to the local phenomenon of delayed hypersensivity.
\end{abstract}

(Accepted for pubication October 2, 1976)

\section{Introduction}

There is considerable evidence that cellmediated immune mechanisms may be involved in the initiation and progression of gingival and periodontal lesions (Ivanyi \& Lehner 1970, 1971a, Ivanyi, Wilton \& Lehner 1972, Horton, Leikin \& Oppenheim 1972, Nobreus, Attström \& Egelberg 1974a, b, Lang \& Smith 1976, 1977). This evidence has been derived largely from in vitro cor- relates of cell-mediated immunity (CMI). These assays are intended to reflect the systemic status of the host towards a particular immunogen, primarily as a measurement of immunologic memory. One of the most reproducible and quantitatively measurable assays is lymphocyte transformation (Thor 1968). However, the level of lymphocyte transformation may be affected specifically or nonspecifically by several fac- 
tors. In vitro problens, including antigen dose-response relationships (Kiger, Wright \& Creamer 1974, Lang \& Smith 1976) and the addition of serum to calture (Ivanyi \& Lehner 1971b), can alter results. Changes in the host's CMI due to aging (Gerber \& Brown 1974, Weksler \& Huitteroth 1974) can also invalidate findings from groups differing in age.

Most of the previous work dealing with CMI and periodontal disease has utilized laboratory grown stains of dental plaque microorganisms or extracts of pooled dental plaque. The significance of these antigens in terms of human periodontal disease can be questioned. Furthermore, if lymphocyte stimulation following antigenic challenge with a particular dental plaque antigen were to increase with increasing severity of periodontal disease as has been reported (Ivanyi \& Lehner 1970, 1971a, Horton et al. 1972), the stimulation tests would be expected to correlate with all the clinical parameters used to assess periodontal condition providing these parameters truly reflect that existing periodontal condition.

The purpose of the present study is to correlate the blastogenic response of peripheral blood lymphocytes after stimulation with human dental plaque sonicates with the following clinical estimates of periodontal condition:

a) the amount of plaque present at the gingival margin;

b) the degree of gingival inflammation;

c) the depth of periodontal pockets;

d) the degree of loss of periodontal support.

\section{Material and Methods}

Forty-eight subjects in excellent general health, age $35-45$ years, with at least 20 teeth were selected on the basis of availability during routine screening at The University of Michigan School of Dentistry. The patients had not received periodontal therapy, other than routine prophylaxis, for at least the last five years.

Following calibration of the examiner (N.P.L.) plaque was scored according to the Plaque Index System (PI I) (Silness \& Löe 1964) and gingival health was assessed according to the criteria of the Gingival Index System (GI) (Löe \& Silness 1963). The depth of the gingival sulcus or the periodontal pocket (PD) was measured using a calibrated MI periodontal probe (Marquis Dental Mfg. Co., 2005 East 17th Avec., Denver, Colo 80206) and loss of periodontal support (LA) in relation to the cementoenamel junction (Ramfjord 1959, Glavind \& Löe 1967) was determined. All teeth present were scored on the mesiobuccal, distobuccal, facial and oral aspects and mean PII, GI, PD and LA were calculated for each participant.

At the time of the clinical examination, $25 \mathrm{ml}$ of peripheral blood was collected from the antecubital fossa using a heparinized (Liquaemin Sodium, Organon Inc., West Orange, New Jersey) syringe.

\section{Lymphocyte transformation test}

The antigens were derived from Veillonella alcalescens, Fusobacterium nucleatum, Bacteroides melaninogenicus, Actinomyces viscosus, Actinomyces naeslundii, Streptococcus sanguis and three week old pooled dental plaque. Phytohemagglutinin (PHA-P) served as a positive control while buffered saline ( $\mathrm{pH}$ 7.4) provided negative controls. The cultures were incubated, harwested and assayed for DNA synthesis according to the methods previously described (Lang \& Smith, 1977).

Stimulation indices (SI) and Delta disintegrations per minute ( $\triangle$ DPM) were calculated according to the following formula:

$$
\mathrm{SI}=\frac{\text { DPM antigen }}{\text { DPM saline }}
$$

$\triangle$ DPM $=$ DPM antigen - DPM saline 
Table 1.

Regression analysis of the relationship between clinical parameters and SI

\begin{tabular}{|c|c|c|c|c|}
\hline & F-statistics & $\begin{array}{c}\text { Significance } \\
P \text { value }\end{array}$ & $\begin{array}{c}\text { Mitultiple } \\
\text { R }\end{array}$ & S.E. \\
\hline PHA & .7284 & .5775 & .2519 & 69.137 \\
\hline V. alcalescens & 1.0746 & .3809 & .3015 & 2.458 \\
\hline B. melaninogenicus & 5.7297 & $.0009^{* *}$ & .5896 & .788 \\
\hline F. nucleatum & 1.4639 & .2298 & .3462 & 1.890 \\
\hline A. viscosus & 3.8907 & $.0088 * *$ & .5155 & 2.013 \\
\hline A. naesllundii & 3.3405 & $.0181^{*}$ & .4869 & 1.263 \\
\hline S. sanguis & .2899 & .8830 & .7620 & 1.136 \\
\hline Pooled plaque & $1.1 \pi 72$ & .3343 & $.3 \sharp 42$ & 1.739 \\
\hline
\end{tabular}

$* p<0.05 \quad * * p<0.01$.

In order to correlate the clinical findings with the in witro assay DPM, multiple regression analyses were performed for each patient's SI and $\triangle$ DPM for all antigens and PHA-P with all clinical parameters in all 48 subjects. Although dose response relationships can be derived from the data, only peak SI or peak $\triangle$ DPM are reported.

\section{Results}

The positive control assay showed a PHA-P stimulation which ranged from 1594 to 26441 DPM with a mean value of 6125 .

Stimulation indices ranged from 25 to $>300$ with a mean value of $\mathrm{SI}=105$ in- dicating a positive assay for all the participants of the study. The background counts were generally below 80 DPM.

Since PII, GI, PD and LA are dependent on each other, they cannot be analyzed as independent variables. The results of regression analysis for the relationships between all clinical parameters and the SI is shown in Table I while Table II gives the corresponding values for $\triangle$ DPM. From these two Tables it can be seen that the only antigens which stimulated blast cell transformation in such a way as to correlate: with any clinical parameters were $B$. melaninogenicus, $A$. viscosus and $A$. naeslundit. Only these three organisms, which showed

Table 2.

Regression analysis of the relationship between clinical parameters and $\triangle D P M$

\begin{tabular}{|c|c|c|c|c|}
\hline & F-statistics & $\begin{array}{c}\text { Significance } \\
\text { p value }\end{array}$ & $\begin{array}{l}\text { Multiple } \\
\text { R }\end{array}$ & S.E. \\
\hline PHA & .4268 & .7884 & .1954 & 4088.7 \\
\hline V. alcalescens & 1.4617 & .2305 & .3460 & 134.15 \\
\hline B. melaninogenicus & 3.4192 & $.0163^{* k}$ & .4912 & 75.42 \\
\hline F. nucleatum & 1.3924 & .2527 & .3389 & 143.04 \\
\hline A. Vlscosus & 4.6107 & $.0035^{\star *}$ & .5479 & 126.88 \\
\hline A. naeslundii & 2.7951 & $.0377^{*}$ & .4543 & 87,62 \\
\hline s. sanguis & .2273 & 9218 & .1439 & 86.17 \\
\hline Pooled placiue & 1.3452 & 2688 & .3335 & 87.95 \\
\hline
\end{tabular}

$=p<0.05 * p<0.01$. 
Table 3.

Correlation coefficients and level of significance of the relationship between PII, GI, PD, $\mathrm{LA}$ and blast cell transformation for the $\mathrm{Ag}$ with significant regression analysis

\begin{tabular}{|c|c|c|c|c|}
\hline & \multicolumn{4}{|c|}{ Gorrelation coefficients for SI and } \\
\hline & $\mathrm{P} \mid \mathrm{I}$ & GI & $\mathrm{PD}$ & LA \\
\hline B. melaninogenicus & $.4715^{* *}$ & $.4902^{* *}$ & $.5799^{* *}$ & $.5618^{* *}$ \\
\hline A. viscosus & $.4977^{* *}$ & $.4746^{\star *}$ & $.3188^{*}$ & $.3004^{\star}$ \\
\hline A. Inaeslundil & $.3441^{*}$ & $.3604^{*}$ & $.4165^{* *}$ & .2550 N.S. \\
\hline
\end{tabular}

\begin{tabular}{llccc}
\hline & \multicolumn{3}{c}{ Correlation coefficients for $\triangle$ DPM and } \\
\hline B. melaninogenicus & PI I & GI & PD & $.4509^{* *}$ \\
A. viscosus & $.3733^{* *}$ & $.3760^{* * *}$ & $.4838^{* *}$ \\
A. naeslundii & $.5245^{* *}$ & $.4722^{* *}$ & $.3359^{*}$ & $.3583^{*}$ \\
\hline
\end{tabular}

* $p<0.05 \quad$ ** $p<0.01 \quad$ N.S. not signiticant

a significance in the regression analysis, were further analyzed.

The individual clinical parameters were then correlated separately with the SI or $\triangle$ DPM for all subjects. The results are shown in Table III. It is apparent that the correlation coefficients between all clinical parameters and blast-cell transformation are highly significant $(\mathrm{p}<0.01)$ for $B$. melaninogenicus. However, the correlation coefficients between SI or $\triangle$ DPM and PD or LA seem to be higher (.5799 and .5618) than when these parameters are correlated to the PII and GI (.4715 and .4902).

For the two Actinomyces strains this relationship appears to be reversed. The correlation coefficients for PII and GI (.4977 and .4746) and the Iymphocyte response are of a greater significance $(\mathrm{p}<$ 0.01 ) than those for PD and $\mathbb{L} A$ (.3188 and $.3004)$ which are only significant at the $95 \%$ level of confidence. Similar relationships exist for $A$. naeslundit. However, this organism does not show a significance between the SI and LA $(r=.2550)$.

These findings are also illustrated in Figures 1 and 2. Figure 1a shows a scatter plot of the relationship between peak SI and PD for stimulation with $B$. melaninogenicus, while Figure $1 \mathrm{~b}$ demonstrates the relationship between SI and LA for the same organism. Peak SI for A. viscosus are plotted against mean PlI in Figure 2a and mean GI in Figure 2b.

It may be noted that although the multiple regression analysis of the relationship between stimulation of PBL with $F$. nucleatum and clinical parameters was not significant, there was a low but significant correlation $(\mathrm{p}<0.05)$ between stimulation with F. nucleatum and $\mathrm{PD}$ (SI: $\mathrm{r}=.3387, \Delta$ DPM: $\mathrm{r}=.3757$ ).

All correlation coefficients of the relationship between any of the other clinical parameters and the rest of the antigens tested or PHA were not significant.

\section{Discussion}

If lymphocyte transformation responses following stimulation with dental plaque organisms were to reflect the periodontal disease status, a positive correlation would have to be found between clinical para- 

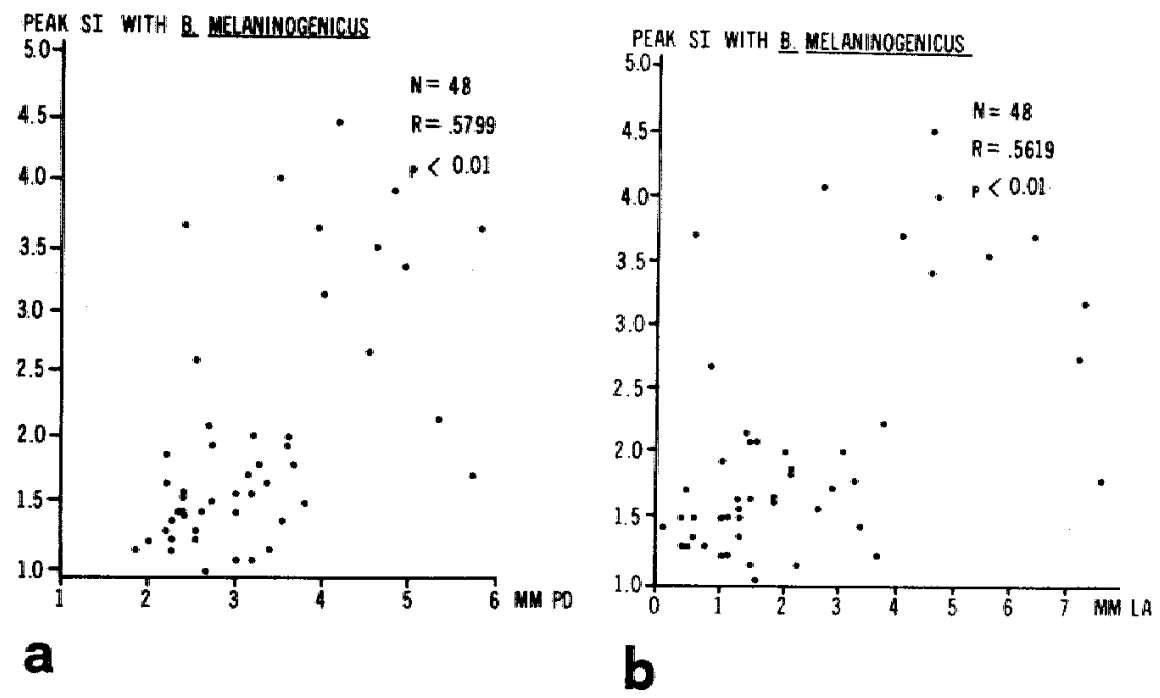

Fig. 1. Scatter plot of the lymphocyte transformation test with B. melaninogenicus, a) Relationship between peak stimulation ündices (Si) and pocket depth (PD). b) Relationship between peak stimulation indices (SI) and loss of attachment (LA).

meters and the lymphocyte transformation test of a patient.

In this study there was generally no statistically significant correlation between the mean peak SI of most antigens in all subjects and their clinical parameters. These firndings tend to support the conclusions of Kiger et al. (1974) who refuted the concept of linearly increasing SI with increasing deterioration of the periodontal tissues, proposed by Ivanyi \& Lehner $(1970,1971)$ and supported by Horton et al. (1972).

Significant regression analysis were only found for SI with $B$. melaninogenicus, $A$. viscosus and $A$. naeslundii. However, the correlation coefficients with the clinical parameters were rather low $(0.47-0.58$ for B. melarinagenicus, $0.30-0.50$ for $A$. viscosus and $0.26-0.42$ for $A$. naeslundii). The fact that the SI with $B$. melaninogenicus showed higher correlations with PD and LA than with PII and GI merely supports the concept that this organism is predominantly associated with deep periodontal pockets (Lang \& Smith 1977). This is not surprising when considering the nutrient requirements of this organism (Evans 1951, Lev 1958, Gibbons \& MacDonald 1960). Likewise, the higher correlations of PII and GI with the SI obtained by stimulation with $A$. viscosus support an association of this organism with developing and established gingivitis (Lang \&. Smith 1977). A. viscosus and A. israeiti were the only organisms which increased not only in bulk but in proportion during a recent experimental gingivitis in man (Loesche \& Syed 1975, Syed, Loesche \& Löe 1975).

This would support a concept of a possible pathogenic potential of this organism. If lymphocyte transformation tests were to serve as a satisfactory laboratory diagnostic 

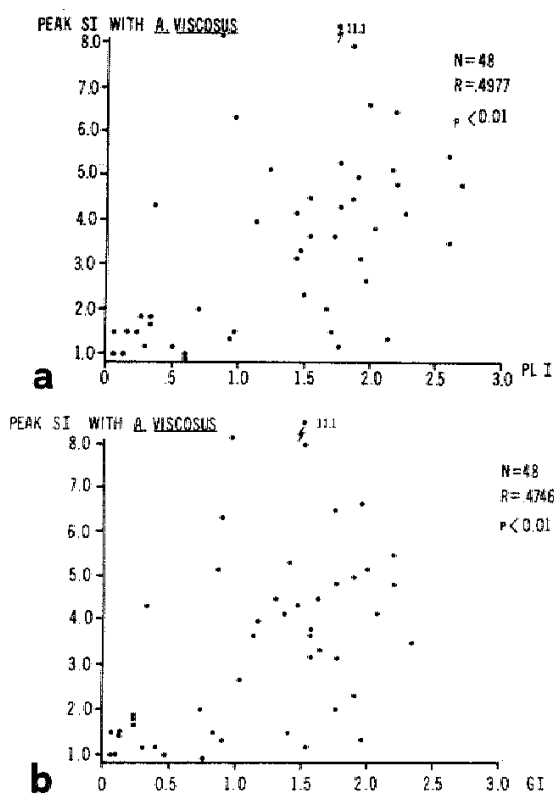

Fig. 2. Scatter plot of the lymphocyte transformation test with A. viscosus. a) Rellationship between peaik stimulation index (SI) and plaque Index (PI II. b) Relationship between peak stimulation index (SI) and gingival index (GI).

test for the determination of the severity of periodontal disease in individual patients or populations, $A$. viscosus may be an important organism to use as an antigen.

Morphometric studies on chronic gingivitis lesions in man (Schroeder \& Page 1972, Schroeder, Münzel-Pedrazzoli \& Page 1973) have indicated that a marked increase of medium-sized lymphocytes is associated with a decrease in number of fibroblasts as the infiltrated connective tissue increases in size. However, it is unclear whether these cells are multiplying at the site of the lesion or are recruited from other sites. There is sone evidence for the latter possibility (Mackaness 1971). Since the lymphocytefibroblast ratio of $0.8: 1$ for non-infiltrated connective tissue increases sixfold to $5: 1$ in infiltrated connective tissue of the gingival lesion (Schroeder, Münzel-Pedrazzoli \& Page 1973), it is quite possible that cellmediated immunological processes may influence the pathogenesis of periodontal lesions. Despite the fact that other mechanisms such as phagocytosis by macrophages (Parakkal 1969), enzymatic (Fullmer \& Gibson 1966, Fullmer et al. 1969) as well as lysosomal activity (Freedman, Listgarten \& Taichman 1968, Lange \& Schroeder 1971) and bacterial products (Mergenhagen 1967) in association with the complement system (Snydermann 1972, 1973) may also contribute to the loss of periodontal supporting structures, cell mediated immune responses to some pathogenic organisms of the oral cavity have been demonstrated (Ivanyi \& Lehner 1970, 1971a, b, Horton et al. 1972, Guggenheim \& Schroeder 1974, Patters et al. 1976, Lang \& Smith (1977). Therefore, lymphocyte transformation tests may have a potential of revealing the clinical condition of periodontal patients, if the relevant microorganisms are used as an antigen. Future research will have to concentrate on standardization of the assay systems to facilitate comparison of blastogenesis results from different laboratories (Patters et al. 1976).

\section{References}

Evans, R. J. 1951. Haematin as a growth factor for striat anaerobe, Fusiform: s melaninogenicts. Proc. Soc. Gen. Microbiol. 5: XIX.

Freedman, H. L., Listgarten, M. A. \& Taichman, N. S. 1968. Electron microscopic features of chronically inflamed humant gingiva. J. Periodontal Res. 3: 313-327.

Fullmer, H. M. \& Gibson, W. A. 1966. Collagenolytic activity in gingiva of man. Nature 209: 728-729.

Fullmer, H. M., Gibson, W. A., Lazarus, G. S., Bladen, A. \& Whedon, K. A 1969. The origin of collagenase in periodontal tissues of man. J. Dent. Res. 48: 646-651.

Gerber, J. D. \& Brown, A. L. 1974. Effect of 
development and aging on the response of canine lymphocytes to phytohemagglutinin. Infect. Immunity 10: 695-699.

Gibbons, R. J. \& MacDonald, J. B. 1960. Hemin and vitamin $K$ compounds as required factors for the cultivation of certain strains of Bacteroides melanimogenicus. $J$. Bact. 80: 164-170.

Glavind, L. \& Löe, H. 1967. Errors in the clinical assessment of periodontal destruction. J. Periodontal Res. 2: 180-184.

Guggenheim, B. \& Schroeder, H. E. 1974. Reactions in the periodontium to continuous antigenic stimulation in sensitized gnotobiotic rats. Infect. Immunity 10: 565-577.

Horton, J. E., Leikin, S. \& Oppenheim, J. J. 1972. Human lymphoproliferative reaction to saliva and dental plaque deposits: an in vitro correlation with periodontal disease. J. Periodont. 43: 522-527.

Ivanyi, $\mathbb{L}$. \& Lehner, T. 1970 . Stimulation of lymphocyte transformation by bacterial antigens in patients with periodontal disease. Archs. oral Biol. 15: 1089-1096.

Ivanyi, L. \& Lehner, T. 1971a. Lymphocyte transformation by sonicates of dental plaque in human periodontal disease Archs. oral Biol. 16: 1117-1121.

Ivanyi, L. \& Lehner, T. 1971b. The significance of serum factors in stimulation of lymphocytes from patients with periodontal disease by Veillonella alcalescens. Int. Arch. Allergy 41: $620-627$.

Ivanyi, L., Wilton, J. M. A. \& Lehner, T. 1972. Cell-mediated immumity in periodontal disease; cytotoxicity, migration inhibition and lymphocyte transformation studies. Immunology 22: 141-145.

Kiger, R. D., Wright, W. H. \& Creamer, H. R. 1974. The significance of lymphocyte transformation responses to various microbial strains. J Periodontol. 45: 780-785.

Lang, N. P. \& Smith, F. N. 1976. Lymphocyte response to T-cell mitogen during experimental gingivitis in man. Inf. Immunity. 13: 108-113.

Lang, N. P. \& Smith, F. N. 1977. Lymphocyte blastogenesis to plaque antigens in human periodontal disease. I. Populations of varying severity of disease. J. Periodontal Res. 12: submitted for publication.

Lange, D. \& Schroeder, H. E. 1971. Cytochemistry and ultrastructure of gingival sulcus cells. Helv. odont. Acta 15: 65-86, Suppl. IV.

Lev, M. 1958. Apparent requirements for vita- min $\mathrm{K}$ of rumen strains of Fusiformis nigrescens. Nature 181: 203-204.

Löe, H. \& Silness, J. 1963. Periodontal disease in pregnancy. Prevalence and severity. Acta odont. Scand. 21: 533-551.

Loesche, W. J. \& Syed, S. A. 1975. Bacteriology of dental plaque in experimental gingivitis. I. Relationship between gingivitis and flora. AADR abstr. e.g. \# 108. 53rd general session, New York, J. Dent. Res., 54: (Special issue A) 71 .

Mackaness, G. B. 1971. Cell-mediated immunity. In: Cellular interactions in the humam response. 2nd Int. Convoc. Immunol. Cohen, S., Cudkowicz, G. \& MoCluskey, R. T. (eds.) Karger, Basel. pp. 241-248.

Mergenhagen, S. E. 1967. Nature and significance of somatic antigens of oral bacteria. J. Dent. Res. 46: 46-52.

Nobréus, N. Attström, R. \& Egelberg, J. 1974a. Effect of anti-thymocyte serum on development of gingivitis in dogs. $J$. Periodont. Res. 9: 227-235.

Nobréus, N., Attström, R. \& Egelberg, J. $1974 \mathrm{~b}$. Effect of anti-thymocyte serum on chronic gingival inflammation in dogs. $J$. Periodont. Res. 9: 236-244.

Parakkal, P. F. 1969. Involvement of macrophages in collagen resorption. J. Cell. Biol. 41: $345-354$.

Patters, M. R. et al. 1976. Blastogenic response of human lymphocytes to oral bacterial antigens: comparison of individuals with periodontal disease to normal and edentulous subjects. Int. Immunity 14: 12131220 .

Perkins, W. D., Robson, L. C. \& Schwarz, M. R. 1975. Immunoglobulin-positive cells: their appearance in the mixed lymphocyte reaction. Science 188: 365-366.

Ramfjord, S. P. 1959. Indices for prevalence and incidence of periodontal disease. $J$. Periodontol. 30: 51-59.

Schroeder, H. E. \& Page, R. 1972. Lymphocytefibroblast interaction in the pathogenesis of inflammatory gingival disease, Experientia 28: $1228-1230$.

Schroeder, H. En, Münzel-Pedrazzoli, S. \& Page, R. 1973. Correlated morphometric and biochemical analysis of gingival tissute in early chronic gingivitis in man. Arch oral Biol. 18: 899-923.

Silness, J. \& Löe, H. 1964. Periodontal disease in pregnancy. II. Correlation between oral hygiene and periodontal condition. Acta Odont. Scand. 22: 121-135. 
Snyderman, R. 1972. Role of endotoxin and complement in periodontal tissue destruction. J. Dent. Res. 51: Suppl. 2, 356-361.

Snyderman, R. 1973. The role of the immune response in the developnent of periodontal disease. Int. Dent. J. 23: 310-316.

Syed, S. A., Loesche, W. J. \& Löe, H. 1975. Bacteriology of dental plaque in experimental gingivitis 2: Relationship between time, plaque score and flora. AADR abstr. e. g., \#109, 53rd general session, New York, J. Dent. Res. 54: (Special issue A), 72.

Thor, D. E. 1968. Human delayed hypersensitivity: an in vitro correlate and transfer by an RNA extract. Federation Proc. 27: 16-20. Weksler, M. E. \& Huitteroth, T. H. 1974. Impaired lymphocyte function in aged humans. J. Clin. Invest. 53: 99-104. 
This document is a scanned copy of a printed document. No warranty is given about the accuracy of the copy. Users should refer to the original published version of the material. 